\title{
Elementos pré-fabricados e suas vantagens no cronograma físico-financeiro
}

\author{
Prefabricated elements and their advantages in the physical-financial schedule \\ Elementos prefabricados y sus ventajas en el cronograma físico-financiero
}

Recebido: 12/12/2021 | Revisado: 18/12/2021 | Aceito: 29/12/2021 | Publicado: 06/01/2022

\author{
Tatiana Brandão Honorato \\ ORCID: https://orcid.org/0000-0002-1419-0373 \\ Universidade Federal do Rio de Janeiro, Brasil \\ E-mail: t_brandao25@yahoo.com.br
}

\begin{abstract}
Resumo
Os elementos pré-fabricados chegam ao Brasil como inovação para a construção civil. Ainda pouco difundidos, acarretam vantagens no cronograma físico financeiro da obra em empreendimentos de muitos pavimentos e com curto prazo. A industrialização da construção civil vem aumentando a produção em série de cozinhas e banheiros, sendo este mais utilizado. Os banheiros são fabricados numa linha de produção industrial e chegam prontos à obra, respeitando a arquitetura do projeto e especificações do cliente, bastando posiciona-los na área previamente planejada e conectá-los às redes de água, esgoto e energia. Desta forma, todas as etapas de controle de materiais, acabamentos, execução de instalações e controle de qualidade são realizados na fábrica. Os revestimentos, instalações hidráulicas, elétricas e todos os acessórios são instalados na linha de montagem, evitando assim retrabalho e desperdício de materiais durante a obra. Depois de finalizados, os banheiros prontos (ou pré-fabricados) são inspecionados e aferidos pelo controle de qualidade nas várias etapas: estanqueidade, vazão, caimento, pressão e circuitos elétricos. Possui várias vantagens na sua utilização como diminuição da mão de obra, redução no cronograma da construção, dentre outros. O presente artigo tem como objetivo analisar a viabilidade técnica e econômica dos Banheiros Prontos e avaliar os prazos de execução dos métodos pré-fabricado e convencional através de estudo de caso. Faz-se imperioso que o referido sistema seja aplicado em grandes empreendimentos que tenham um cronograma curto e com possibilidade de multa em caso de atraso, pois são mais onerosos que os banheiros convencionais.
\end{abstract}

Palavras-chave: Banheiro-pronto; Pré-fabricado; Vantagens; Cronograma; Controle de qualidade.

\begin{abstract}
Prefabricated elements arrive in Brazil as an innovation for civil construction. Still not widespread, they bring advantages in the physical and financial schedule of the work in projects with many floors and with a short term. The industrialization of civil construction has been increasing the series production of kitchens and bathrooms, which are the most used. The bathrooms are manufactured on an industrial production line and arrive ready for work, respecting the project's architecture and customer specifications, simply placing them in the previously planned area and connecting them to the water, sewage and energy networks. In this way, all steps of material control, finishing, installation execution and quality control are carried out at the factory. Coatings, hydraulic and electrical installations and all accessories are installed on the assembly line, thus avoiding rework and waste of materials during the work. Once completed, the finished (or pre-fabricated) bathrooms are inspected and checked by quality control at the various stages: tightness, flow, trim, pressure and electrical circuits. It has several advantages in its use, such as a reduction in labor, reduction in the construction schedule, among others. This article aims to analyze the technical and economic feasibility of Ready-To-Eat Bathrooms and evaluate the deadlines for the execution of prefabricated and conventional methods through a case study. It is imperative that this system be applied in large projects that have a short schedule and with the possibility of fines in case of delay, as they are more expensive than conventional bathrooms.
\end{abstract}

Keywords: Ready-made bathroom; Prefabricated; Advantages; Schedule; Quality control.

\section{Resumen}

Los elementos prefabricados llegan a Brasil como una innovación para la construcción civil. Aún no generalizados, aportan ventajas en el cronograma físico y financiero de la obra en proyectos con muchas plantas y con un corto plazo. La industrialización de la construcción civil ha ido incrementando la producción en serie de cocinas y baños, que son los más utilizados. Los baños se fabrican en una línea de producción industrial y llegan listos para trabajar, respetando la arquitectura del proyecto y las especificaciones del cliente, simplemente colocándolos en el área previamente planificada y conectándolos a las redes de agua, alcantarillado y energía. De esta forma, todos los pasos de control de material, acabado, ejecución de la instalación y control de calidad se realizan en fábrica. En la línea de montaje se instalan revestimientos, instalaciones hidráulicas, eléctricas y todos los accesorios, evitando así retrabajos y desperdicio de materiales durante la obra. Una vez terminados, los baños terminados (o prefabricados) son inspeccionados y controlados por control de calidad en las distintas etapas: estanqueidad, caudal, trimado, presión y circuitos eléctricos. 
Tiene varias ventajas en su uso, como reducción de mano de obra, reducción del cronograma de construcción, entre otras. Este artículo tiene como objetivo analizar la viabilidad técnica y económica de los Baños Listos para Consumir y evaluar los plazos de implementación de métodos prefabricados y convencionales a través de un estudio de caso. Es imperativo que este sistema se aplique en proyectos grandes que tienen un cronograma corto y con posibilidad de multas en caso de retraso, ya que son más costosos que los baños convencionales.

Palabras clave: Baño confeccionado; Prefabricado; Ventajas; Cronograma; Control de calidad.

\section{Introdução}

Com o aumento constante da população, a construção civil tem buscado novos rumos para efetuar as construções de forma rápida e segura. $\mathrm{O}$ processo construtivo convencional esbarra em atrasos no cronograma da obra, desperdício de materiais e técnicas muitas vezes rudimentares. A pesquisa árdua para desenvolver e aplicar novos métodos para o setor se faz necessária.

O atual cenário social e principalmente econômico não apenas do Brasil, mais do mundo, é de incertezas. Isso faz com que as organizações não tenham margens para desperdícios e retrabalhos no desenvolvimento de suas atividades, pois estas anormalidades geram custos adicionais reduzindo a competitividade em um mercado cada vez mais exigente e competitivo (Ferreira et. al., 2021).

Para que a produtividade seja alcançada, é necessário que haja um estudo minucioso, utilizar de métodos eficientes e contínuos, portanto, é a melhor opção, para que os dados obtidos sejam capazes de apresentar um mapeamento dos processos, identificar os desperdícios e movimentações que não têm valor agregado ao cliente, para que melhorias sejam frequentemente apresentadas (Santos et. al., 2020).

Uma das alternativas para aumentar a celeridade da obra são os pré-fabricados, especificamente o banheiro pronto. Por conseguinte, o tema desta pesquisa é sobre a vantagem no cronograma físico e financeiro da obra com a contratação de elementos pré-fabricados, sendo que o enfoque será no banheiro pronto.

O banheiro pronto ou pré-fabricado é um sistema no qual os banheiros são construídos em linha de produção, e podem ser executados com concreto armado ou drywall. Seu uso é um instrumento de racionalização da obra, pois configura uma mudança na organização dos processos tradicionais de construção e visa adequar a tecnologia ao canteiro de obras, colaborando também para a melhor utilização dos materiais e redução de custos.

O objetivo é analisar a viabilidade de aplicação dos banheiros prontos visando a parte técnica e econômica e avaliar seus prazos de execução nos métodos pré-fabricado e convencional. Espera-se que com a difusão deste sistema, a produção industrial tenha mais estímulos governamentais e que fomente a concorrência entre fabricantes, diminuindo do valor do banheiro pré-fabricado e ampliação seu uso.

A questão foi embasada através da revisão bibliográfica do contexto histórico relacionado a construção civil de modo geral, seu desenvolvimento no Brasil e, posteriormente, veremos os elementos pré-fabricados. Fizeram-se indagações sobre no banheiro pronto e suas particularidades no canteiro de obras, além de estudo de caso com auxílio de autores como Rodrigo Lopes, Vasconcelos e Carlos Kume.

\section{Metodologia}

Segundo Estrela (2018), a lógica de uma pesquisa inclui objetivos claros que apontam para a melhora e mudança na qualidade de vida do indivíduo, ao incremento e poder econômico do país e, consequentemente, à geração de empregos.

Como esforço de pesquisa, o estudo de caso contribui, de forma inigualável, para a compreensão que temos dos fenômenos individuais, organizacionais, sociais e políticos Yin (2015).

Um caso, para ser chamado de "caso", tem que ter alguma particularidade que o diferencie, tem que ser especial. Em geral, faz-se o estudo de um caso, e não de vários casos. O caso tem que ser descrito e analisado do modo mais detalhado e 
completo possível Pereira A. S. et al. (2018).

A metodologia adotada tem como base a descrição de todas as etapas envolvidas no processo produtivo do banheiro pronto, desde a elaboração do projeto até o posicionamento final da célula de banheiro.

Estará, também, presente no trabalho, como estudo de caso, exemplo de aplicação do sistema banheiro pronto na obra do Hotel Ibis Budget na Praia de Botafogo, Rio de Janeiro.

De acordo com Ludke (2013), é conveniente que no processo de delimitação progressiva do foco principal da investigação sejam também formuladas algumas questões ou proposições específicas, em torno das quais a atividade de coleta passa a ser sistematizada. Além de favorecer a análise, essas questões possibilitam a articulação entre os pressupostos teóricos do estudo e os dados da realidade.

O conhecimento técnico adquirido com a experiência nesta obra auxiliará na análise crítica dos processos. Por fim, será utilizado o método comparativo para avaliar a viabilidade econômica dos banheiros pré-fabricados, ao confrontar o orçamento do banheiro pronto e do fabricado in loco, com as mesmas características.

\section{Resultados e Discussão}

\subsection{Segunda revolução industrial}

No final século XIX, iniciou-se a segunda revolução industrial que terminou durante a Segunda Guerra Mundial (1939 - 1945). Vários avanços tecnológicos, advindos ainda da primeira revolução industrial, obtiveram melhoras e maior abrangência durante esse período, entre eles podemos destacar a utilização em maior escala da energia elétrica, o uso do motor a explosão, do petróleo, alumino, aço, dentre outros.

O aprimoramento destas tecnologias levou a aceleração do ritmo industrial em diversas partes do mundo e levou os donos de capital e meios de produção a direcionar recursos para criar novas tecnologias ou procedimentos produtivos, com o intuito de aperfeiçoar, dinamizar e acelerar a produtividade, bem como aumentar os percentuais de lucro.

Estudiosos elaboraram várias teorias e máquinas para obtenção na redução dos custos e maior celeridade produtiva. Dois sistemas de produção ficaram muito conhecidos e levaram a grandes avanços. São eles o Taylorismo e o Fordismo.

\subsubsection{Taylorismo}

Criado pelo engenheiro mecânico Frederick Winslow Taylor, no final do século XIX, o taylorismo, também conhecido como administração cientifica, é um sistema que consiste no pressuposto que cada trabalhador deveria realizar uma atividade determinada e especializar-se nela, independente das demais etapas da produção, levando a produção em larga escala. Sua principal característica é a organização e divisão de tarefas dentro de uma empresa com o objetivo de obter o máximo de rendimento e eficiência com o mínimo de tempo.

\subsubsection{Fordismo}

Este modo de produção, criado por Henry Ford em 1914, é um modelo que revolucionou a produção industrial no início do século XX. Ele fez uso em suas fábricas de esteiras promovendo assim o não deslocamento dos funcionários e, somado a isto, as técnicas do Taylorismo, como a padronização e a simplificação, corroboraram para o aumento da produção em massa, ou seja, o maior número de produtos no menor tempo possível. Ford foi o precursor da primeira linha de montagem automatizada.

\subsubsection{Industrialização no Brasil}

O desenvolvimento industrial no Brasil começou no final do século XIX, quando as primeiras indústrias instalaramse no Rio de Janeiro e em São Paulo. 
Na primeira administração de Getúlio Vargas (1930 - 1945), a indústria brasileira ganhou grande impulso. Sua intenção era efetivar mais indústrias no país para que não houvesse dependência externa. A indústria beneficiou-se com o fim da Segunda Guerra já que as indústrias europeias precisavam importar produtos de outros países.

Com Juscelino Kubitschek (1956 - 1961), o desenvolvimento ganhou novas feições. Abriu a economia para o capital internacional, o que atraiu as multinacionais para o país, como as montadoras de veículos Ford, Volks, dentre outras.

\subsubsection{Industrialização da construção civil}

Através desta evolução industrial começaram a ser desenvolvidas novas maquinas e tecnologias para a produção de bens. A construção vem, nos últimos anos, ganhando uma ampla participação no Produto Interno Bruto (PIB), hoje com $64 \%$. Tornou-se de suma importância melhores meios de trabalho, pois há grande empregabilidade de mão - de - obra no setor, o que acarretou a introdução da indústria nos modos de construção com a utilização dos pré-fabricados e pré-moldados.

A industrialização na construção, conforme Franco (1992), é o processo evolutivo que, através de ações organizacionais e da implementação de inovações tecnológicas, métodos de trabalho, técnicas de planejamento e controle, objetiva incrementar a produtividade, seu nível e aprimorar o desempenho da atividade construtiva.

Segundo Bruna (1976), nos anos 50, no limiar da segunda revolução industrial, o homem começa a ser substituído por mecanismos, o que termina por libertá-lo das repetições em série e permite o fluxo de séries continuamente diversas, bem como adequar a produção às exigências de cada obra. O controle continua humano, mas as diligencias são automatizadas.

\subsection{A origem dos pré-fabricados}

Vasconcelos (2002), afirma que a pré-moldagem deu-se com a invenção do concreto armado, já que seu próprio nascimento ocorreu com a pré-moldagem de elementos.

Chama-se concreto armado a estrutura de concreto que possui em seu interior, armações feitas com barras de aço.

O cimento armado, como era chamado o concreto armado até 1920, foi patenteado pelo francês Joseph Monier, que fabricava vasos e tubos de concreto que, considerando seus vasos muito frágeis, começa a mergulhar na massa de concreto uma malha de aço.

Podemos citar como exemplo de obras com elementos pré-fabricados:

$\checkmark \quad$ No inicio do século XX, o arquiteto John Brodie, desenvolve o sistema de painéis pré-fabricados.

$\checkmark$ Em 1907, foi criado o método "Tilt-up" onde as paredes eram moldadas na horizontal. A Edison Portland Corporation, pertencente a Thomas Alva Edson, produziu, no canteiro, todas as peças pré-moldadas para construção de um edifício industrial nos EUA.

A norma NBR 9062 (1985), que versa sobre o projeto e a execução de estruturas de concreto pré-moldado, define-os

como:

"elemento que é executado fora do local de utilização definitiva da estrutura, com controle de qualidade menos rigorosos, devem ser inspecionados individualmente, ou por lotes, através de inspetores do próprio construtor, da fiscalização do proprietário ou de organizações especializadas, dispensando-se a existência de laboratório e demais instalações congêneres".

A mesma norma define os elementos pré-fabricados como:

"elementos pré-moldados, executado industrialmente, mesmo em instalações temporárias no canteiro de obras, sob condições rigorosas de controle de qualidade. A inspeção das etapas de produção compreende pelo menos a confecção da armadura, as formas, o amassamento e o lançamento do concreto, o armazenamento o transporte e a montagem." 
Revel (1973) determina que pré-fabricado aplica - se a toda fabricação de elementos na construção civil em indústrias, a partir de matérias primas e semiprodutos cuidadosamente escolhidos e utilizados, sendo em seguida estes elementos transportados à obra para a montagem da edificação.

Salas (1988) considera a utilização dos pré-fabricados de concreto divida em três etapas:

Entre 1950 e 1970, a Segunda Guerra Mundial ocasionou a devastação das edificações e houve a necessidade de construir diversos edifícios, tanto habitacionais quanto escolares e industriais. Havia escassez de mão - de - obra qualificada nos países europeus e a necessidade de grandes construções fez surgir o deslocamento de um grande número de operações do canteiro de obras para indústria surgindo assim a pré-fabricação de alguns materiais. Os sistemas pré-fabricados representaram a tecnologia dominante, onde se procurou aplicar na construção civil conceitos utilizados nas indústrias, como o taylorismo e o fordismo, ou seja, a produção em série com alto índice de repetição dos elementos pré-moldados.

Ordonez (1974), afirma que, no período pós-guerra, principalmente na Europa, houve uma manifestação significativa da industrialização na construção, pois a pré-fabricação ganhou força para auxiliar a construção em larga escala.

No período entre 1970 a 1980 ocorreram vários acidentes com alguns edifícios que utilizaram materiais préfabricados, o que veio a provocar uma rejeição deste tipo de construção e analise de seus conceitos. Como exemplo podemos citar o edifício "Roman Point" na Inglaterra, feito com painéis pré-fabricados que ruiu após uma explosão de gás.

Após 1980, a consolidação dos pré-fabricados vem sendo feita de forma gradual com componentes compatíveis de origens diversas.

Dentro destas fases históricas houve dois ciclos: fechado e o aberto. O ciclo fechado, dado na primeira fase, constituía apenas um fornecedor que não permitia mudanças no projeto original. Já no ciclo aberto, pós 1980, houve uma diversificação de materiais, iniciada na Europa, com a proposta de unir pré-fabricados padronizados a produtos de outros fabricantes possibilitando maior flexibilidade nas construções.

Atualmente, o ciclo flexibilizado prioriza que todo o sistema seja passível de congruência para adequar-se a qualquer tipo arquitetônico. Pode ser utilizada em vigas, lajes, paredes, fundações e pilares. 
Figura 1: A) aplicação de painel pré-fabricado de concreto; B) Método "tilt-up" sendo aplicado numa construção C) Cassino Biarritz, na França
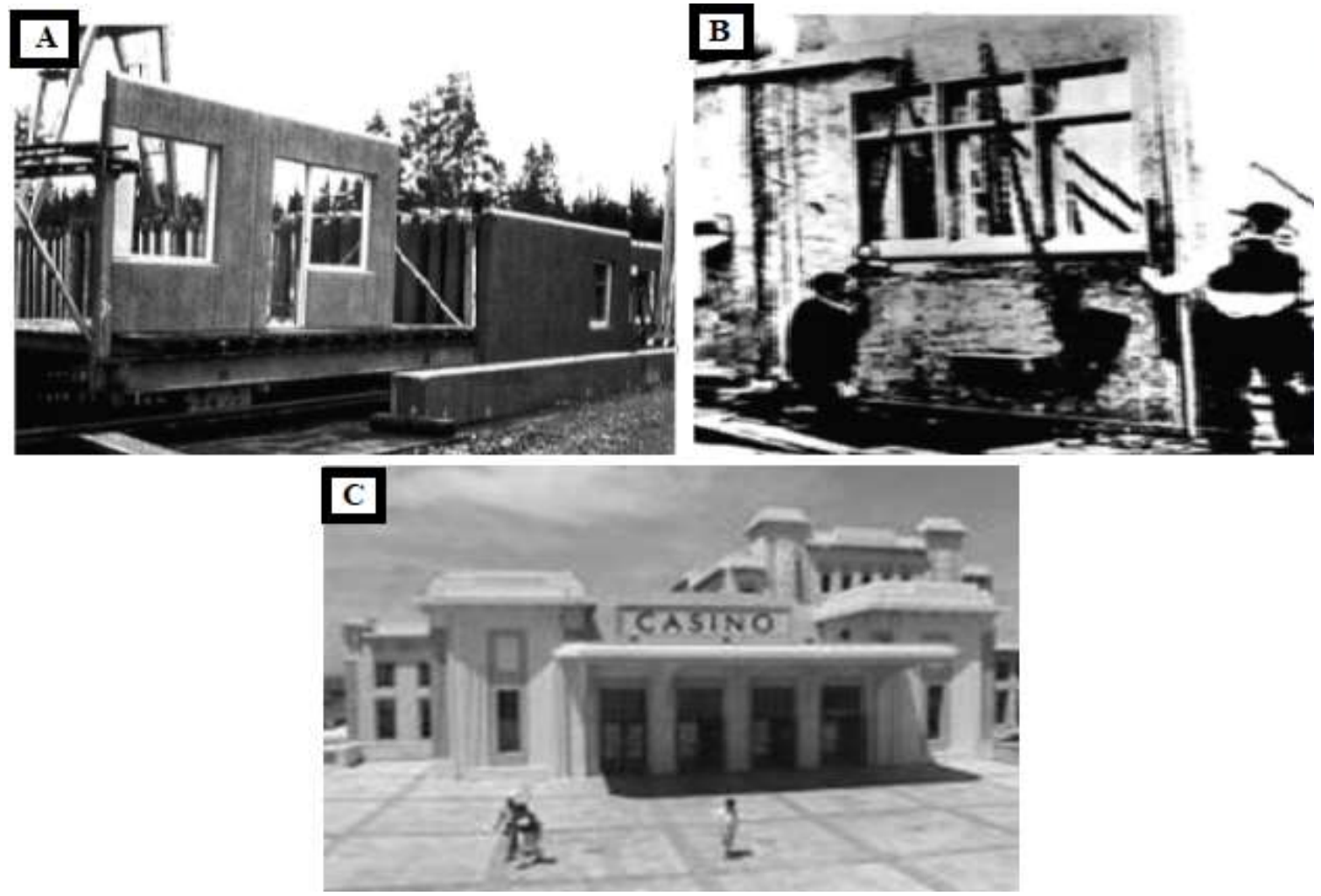

Fontes: A) Bravo, Fabrizio. TCC; B) Leite, David. Tecnologia da pré-fabricação; C) Gonzalez, Francisco M.L. Mecânicas prémoldados.

A Figura 1A mostra a montagem de um painel pré-fabricado em concreto.

A Figura 1B retrata o método "Tilt-up" onde as paredes eram moldadas na horizontal. A Edison Portland Corporation, pertencente a Thomas Alva Edson, produziu, no canteiro, todas as peças pré-moldadas para construção de um edifício industrial nos EUA.

A Figura 1C mostra montagem e execução dos primeiros pré-moldados inloco automatizando o processo construtivo. A primeira obra a utilizar elementos pré-moldados foi o Cassino Biarritz de Paris, na França, segundo Vasconcelos (2002), em 1981, utilizando-se de vigas pré-moldadas.

\subsection{A concepção de banheiro}

Com o desenvolvimento industrial no campo da construção civil, as grandes edificações pedem construções ágeis, contudo seguras. Dentro deste processo, a construção do banheiro requer um minucioso planejamento e harmonização das interfaces por ser uma parte bem complexa da obra e que envolve várias equipes.

Estas precisam de coordenação evitando que o trabalho feito anteriormente possa ser danificado. O banheiro é considerado uma área importante da obra e deve ser cuidadosamente planejado, pois possui instalações de água, esgoto e rede elétrica. Precisa também ser um espaço funcional e confortável, além de ter o tamanho mínimo entre cada elemento por questões de segurança.

Todo o material utilizado como louças, revestimentos cerâmicos e metais sanitários, torna o banheiro o metro quadrado mais caro da obra. Segundo Lopes (2005), a obra de um banheiro abrange mais de 200 itens que devem ser comprados, instalados e verificados, consequentemente, costuma acarretar desperdícios, atrasos e aumento no custo e no prazo de entrega.

Quando iniciamos sua construção o maior problema para um banheiro “in loco” é a inacessibilidade das tubulações o 
que pode acarretar grandes problemas futuros no caso de necessidade de manutenção.

\subsection{Banheiro pronto}

O conceito de banheiro pronto foi desenvolvido na Europa na década de 1980 e envolve a utilização de produtos contemporâneos, visando atender às rigorosas exigências de desempenho, durabilidade e estética.

O banheiro pronto ou pré-fabricado é um sistema tecnológico no qual os banheiros são construídos em linha de produção industrial, podendo ser executados com concreto armado ou drywall (parede de gesso acartonado). Todas as etapas de controle de materiais, instalações, acabamento, passam por um controle de qualidade na própria fábrica, bastando apenas realizar as prumadas de água, esgoto e instalações elétricas no local definitivo.

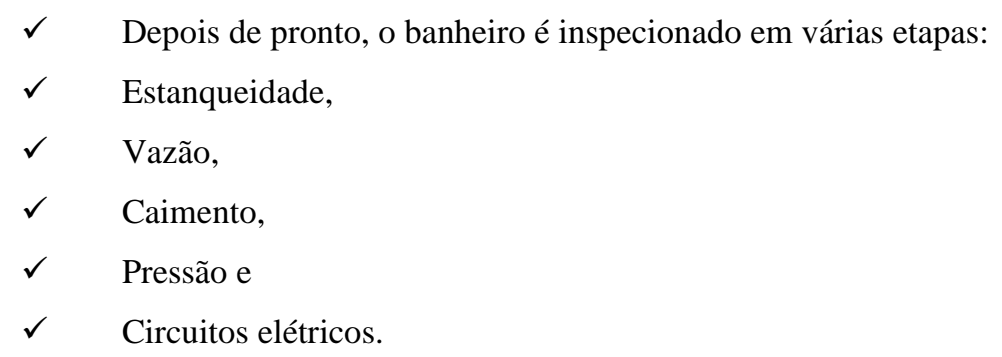

Na Figura 2 pode-se observar um mosaico a concepção do banheiro-pronto em etapas históricas:

Figura 2: A) Planta do Banheiro Dymaxion; B) Standard Prefabricated bathroom unit; C) Banheiro pré-fabricado.

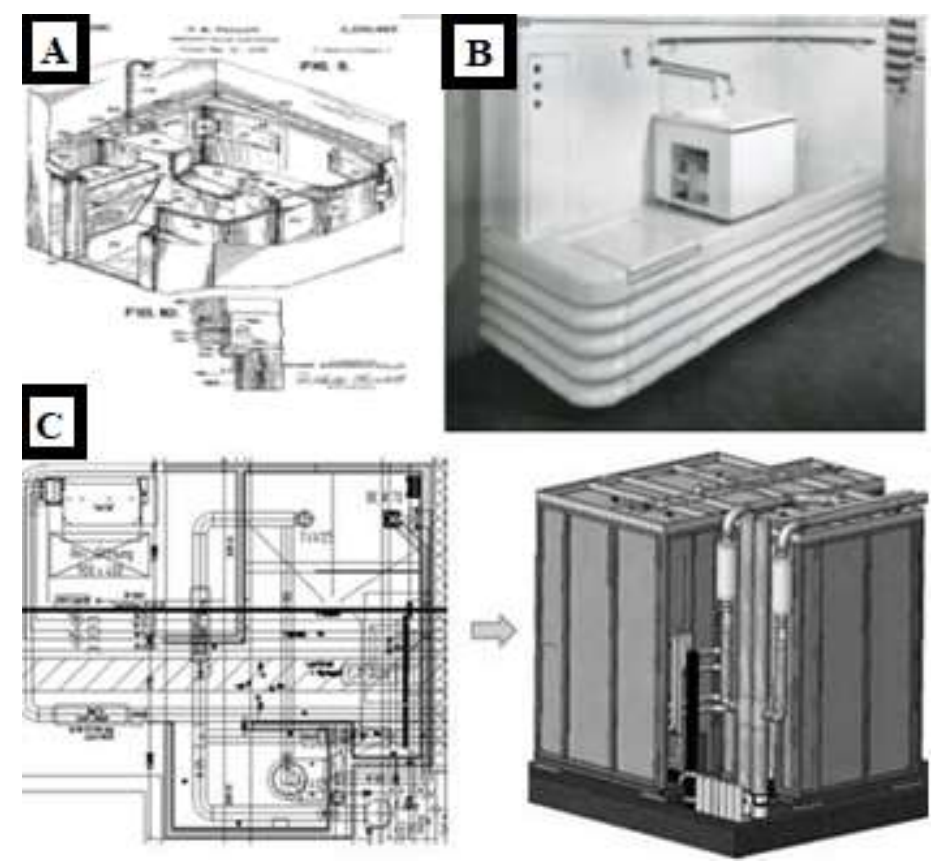

Fontes: A) Patente U 2220482 A, 1940; B) Goldberg, Bertrand. Standart Prefabricated Bathroom C) Hotelier.de.

Apesar do conceito de banheiro pré-fabricado ser recente, Buckminster Fuller, em 1940, patenteou o primeiro banheiro pronto. Preocupado com a falta de saneamento básico e alto custo dos banheiros, Fuller criou o Banheiro Dymaxion, composto por quatro seções de plástico moldado ou de folhas de metal, Figura 2A.

Bertrand Goldberg, um arquiteto, disse: "depois da guerra, eu decidi que a construção de edifícios era bastante arcaica e que deveríamos fazer outra coisa, então eu tentei fazer isso através da construção de banheiros pré-fabricados" (http://bertrandgoldberg.org/). Ele criou o Standard Prefabricated Bathroom, cuja pia foi projetada para rodar sobre o vaso sanitário ou banheira, de modo que a unidade ocupe o mínimo de espaço, Figura 2B. 
Atualmente, banheiro pronto é projetado para ser produzido em instalações industriais, em conformidade com o projeto arquitetônico, e seu padrão de acabamento é integrado ao ambiente que será instalado, sendo produzido em larga escala, adequadas as exigências normativas e especificações da construção. Esta linha industrial de banheiros pré-fabricados ganhou força nos 05 últimos anos, quando uma empresa italiana e outra portuguesa, começaram a produzi-los no Brasil, Figura $2 \mathrm{C}$.

A primeira indústria de banheiros prontos instalada no Brasil foi a Rivoli Tecna Ltda, em 1997. Produz os banheiros pré-fabricados em concreto ou estrutura metálica de gesso acartonado.

A Pavi Brasil, que integra o Grupo Pavicentro de Portugal, foi a primeira a produzir o corpo do banheiro de GFRS (Glass Fiber Reinforced Concrete - concreto reforçado com fibra de vidro) em monobloco.

O setor hoteleiro é o que mais utiliza este recurso para diminuir o tempo da obra e abrir o empreendimento rapidamente, contudo outras construções já estão começando a utilizar os banheiros prontos como: prédios residenciais, hospitais, motéis e prédios comerciais. Quanto maior a quantidade de banheiros, menor o custo final.

Na Figura 3 observa-se a adaptabilidade do modelo construtivo em condomínio residencial e centro comercial:

Figura 3: A)Condomínio Grans Jardins de France; B)Condomínio Grans Jardins de France; C)Centro Comercial Berrini.

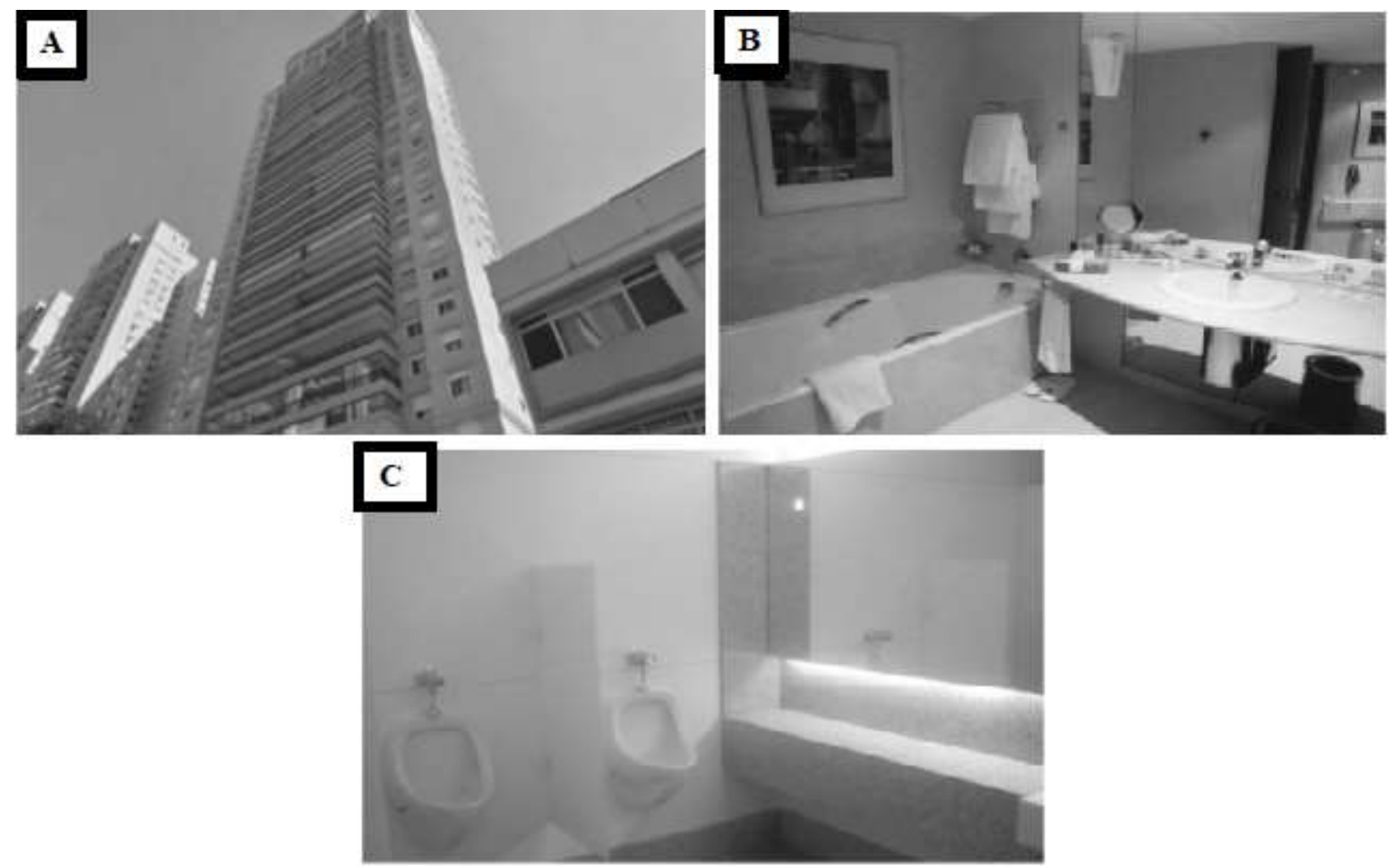

Fontes: 3A e 3B: site Arrobacasa; 3C: site AECweb.

Como exemplo, podemos citar o Condomínio Grands Jardins de France, Figura 3A e 3B, lançado pela Construtora e Incorporadora Inpar, em São Paulo, que teve que utilizar 1.840 módulos de banheiros de concreto armado com acabamento de alto padrão.

Outro exemplo da utilização de banheiros prontos é o Centro Comercial Berrini, Figura 3C, que não foi inicialmente projetado para ter essa tecnologia, mas com a necessidade de entrega rápida, e alta qualidade da construção, o projeto foi reavaliado.

Para sua utilização é necessário o planejamento prévio, ainda no projeto arquitetônico, pois algumas considerações devem ser analisadas como a altura externa total do banheiro şomada com o carro metálico, assim como, deverá existir local e 
acesso livre para estacionamento da carreta, além da grua ou plataforma, para erguê-los na edificação, contudo não há limitações quanto ao tamanho e a forma. Caso tenha dimensões superiores às carretas, pode ser segmentado e unido para instalação final.

Deve-se atentar para as vantagens do banheiro pré-fabricado. Com a sua utilização há menos detritos na obra, e redução do desperdício de materiais, já que os banheiros chegam prontos de fábrica precisando apenas de montagem, prumo e finalização. Adicione-se a este fator que o tempo de entrega é reduzido, eliminando custos indiretos.

\subsubsection{A célula do banheiro pronto}

O corpo do banheiro pré-fabricado é constituído por piso, paredes e teto conforme o projeto arquitetônico, obedecendo à medida anteriormente estabelecida, e devidamente resistente para suportar o transporte e o içamento para o local definitivo na obra.

A altura do corpo do banheiro precisa ser de, no mínimo, 15 centímetros mais baixa que o pé direito do pavimento para que os banheiros possam ser transportados horizontalmente até o local definitivo.

Segundo Amadio (2010), as instalações hidrossanitárias e elétricas são embutidas na parede do banheiro e direcionadas ao shaft (duto vertical por onde passam as tubulações de água, esgoto e elétricas) mantendo as características do sistema convencional. Entretanto, o retrabalho ou possíveis adaptações são resolvidos na fábrica onde há simulação das prumadas de água e esgoto.

Externamente os banheiros prontos necessitam de uma finalização nos seus arredores, exigindo-se uma compatibilização com as relevâncias técnicas de vedações e interfaces.

Banheiros pequenos, que são comuns para hotéis econômicos ou edifícios comerciais, podem ser projetados e construídos em pares ou células gêmeas, onde irão compartilhar um único shaft.

\subsection{Processos de construção}

O processo de construção dos banheiros pré-fabricados envolve 06 etapas: concretagem, montagem, impermeabilização, as instalações elétricas, hidráulicas e de esgoto.

A célula do banheiro pode ser fabricada de vários modos para adaptar-se as características de cada obra, mas a sua configuração e o seu processo de montagem praticamente não se alteram, como mostra o mosaico da Figura 4. 
Figura 4: A)Célula de banheiro pronto; B) Banheiros em pares; C) manta asfáltica; D) banheiro pré-fabricado em fase de montagem.
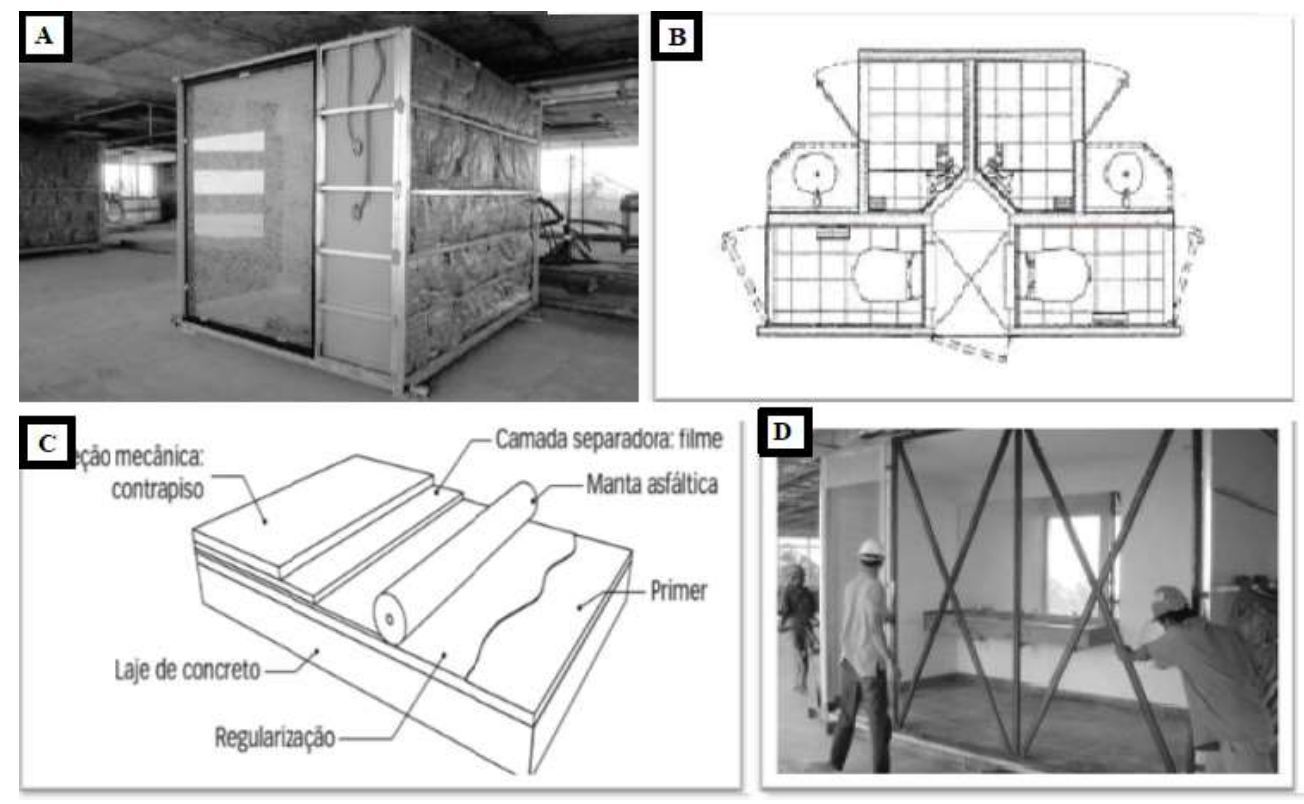

Fontes: A) Lopes, Rodrigo D. 2005; B) Site Terra Magazine; C) Site Construnormas; D) Acervo pessoal.

O concreto utilizado é composto por cimento de alto desempenho, areia de quartzo, areia artificial, pedrisco limpo, aditivo especial e água, que representa uma densidade de $2.450 \mathrm{~kg} / \mathrm{m}^{3}$. Há inserts metálicos em todas as paredes que são responsáveis pela união das delas através de solda MIG garantindo a consolidação do monobloco. A concretagem pode ser feita em fôrmas metálicas ou fôrma monolítica, de maneira que as paredes e o teto sejam concretados ao mesmo tempo.

O monolítico é uma forma padrão, que tem medida fixa de 1,80 x 2,40cm sendo que a altura é variável. Neste mesmo processo, as paredes ganham eletro dutos de $20 \mathrm{~mm}$ para as caixas elétricas internas e externas. É deixado também o eletro dutos para passagem de mangueiras PEX (polietileno reticulado). As peças são concretadas com cura a vapor e são desmoldadas após 12 horas do concreto lançado nas formas. A resistência do concreto com 12 horas é de 8,0 MPA.

Na montagem, Figura 4A, cada banheiro é armado em um carro metálico para seu deslocamento. Nas plataformas, com o auxílio de pontes rolantes, o piso é nivelado e os painéis são ponteados com eletrodos para conferência de alinhamento, esquadro e prumo e posicionado em pares, Figura 4B. Posteriormente, confirmadas as exigências de níveis, os lugares que foram soldados são solidificados através da solda MIG (Metal Inert Gas - fluxo de gás inerte), juntamente com o teto. A tolerância para nivelamento é de, aproximadamente, 01 milímetro.

Depois da limpeza aplica-se o primer e, depois de secar, sobrepõe-se a manta asfáltica na espessura de 3 a 4 milímetros. Este sistema é adotado por se tratar de um material flexível. O piso é totalmente impermeabilizado, assim como as paredes em seu entorno a uma altura de 30 centímetros, Figura 4C. Neste momento são executados os testes de estanqueidade e caimento em todos os banheiros, antes e após a colocação do revestimento. É feita também uma proteção mecânica para nivelamento do piso e proteção da manta asfáltica.

Nesta fase, será feito o acabamento. Os banheiros prontos possuem kits de revestimento. Um gabarito externo em uma mesa de trabalho é executado por um funcionário que faz os cortes para a paginação do banheiro.

Após todo revestimento, instalações hidráulicas e elétricas serem executadas e, também, a aplicação do rejunte serão instalados os acessórios do banheiro, os básicos e aqueles que o cliente solicitar.

O último acabamento interno dos banheiros é a aplicação de silicone nas bancadas e também em todo entorno do piso, teto e da bacia sanitária, Figura 4D. 
A norma técnica para projetos e execução feitos em estruturas de concreto pré-moldado - NBR 9062:2001 é a norma que, por enquanto, norteia as técnicas de aplicação nas obras de banheiros prontos, já que, no momento, não há cláusulas especificas para este tipo de construção.

\subsubsection{Interfaces para implantação do banheiro pronto}

A instalação de um banheiro pré-fabricado solicita alguns requisitos que não são necessários no banheiro "in loco". Dentre eles estão:
$\checkmark \quad$ Complemento do pé direito em gesso acartonado;
$\checkmark \quad$ Desnível do banheiro em relação à laje;
$\checkmark \quad$ Utilização de neoprene para apoio do banheiro sobre a laje.

\section{Estudo de Caso}

O projeto utilizado como exemplo será o hotel da rede Ibis Budget, localizado na Praia de Botafogo, no Rio de Janeiro, Figura 5A. Este possui 14 andares e é composto por 261 quartos, sendo que 246 receberam banheiros pré-fabricados da empresa contratada Tecnobagno, que é especializada na construção de banheiros pré-fabricados em concreto armado e gesso acartonado. O restante foi construído "in loco" para portadores de necessidades especiais.

A necessidade de mais instalações para as olimpíadas fazia parte de um projeto da prefeitura chamado "Pacote Olímpico" para atender a demanda de visitantes durante os jogos. Junto com a padronização dos quartos em toda a rede, são fatores primordiais para a escolha do banheiro pronto neste empreendimento.

No início do projeto, o fabricante recebeu especificações sobre os acabamentos para a confecção do banheiro. Depois de uma análise detalhada, o fornecedor produz um modelo e envia para a aprovação do cliente. Tendo os itens do banheiro aprovados, a empresa Tecnobagno preparou uma planilha de custos, para que o valor dos materiais seja aprovado pelo cliente antes de dar início ao procedimento de compra.

Como o banheiro é totalmente produzido na fábrica, esta possui mais facilidade na compra e estocagem de grandes quantidades de material, o qual pode ser utilizado em outros módulos, e acaba por obter melhores preços no mercado.

Considerando o caso em questão, os banheiros do Ibis Budget Praia de Botafogo, foram adicionados dispositivos antifurto, ou, como antes mencionado, portas provisórias com cadeados utilizadas para prevenir danos ao banheiro durante a construção e eventuais furtos.

A compra de todos os materiais é acompanhada pela construtora, que recebe os pedidos na medida em que os itens são necessários na fábrica. A obra mantém as notas fiscais, entretanto os materiais foram entregues diretamente na Tecnobagno, que iniciou a fabricação dos banheiros enquanto o empreendimento ainda estava na fase de fundação.

Os cronogramas da obra e o tempo de execução dos banheiros prontos devem ser alinhados de forma que não haja prejuízos, já que uma vantagem deste sistema é a redução no período da obra, e algumas partes da mesma dependem da chegada dos módulos.

O banheiro utilizado é do tipo compartimentado, adotando os padrões da rede, com chuveiro e bacia sanitária em espaços definidos e o lavatório fazendo parte do quarto. Os banheiros se unem em formato de U e dividem o mesmo shaft.

No projeto foi antevisto o uso de bacia sanitária com saída horizontal e caixa acoplada, exaustores nos compartimentos confinados e isolamento acústico, feito com lã de vidro entre as folhas de drywall, em toda a célula e nos complementos de pé direito.

Abaixo vemos um exemplo de shaft nesta obra Figura 5C, recebendo as prumadas dos banheiros e na frente os dutos verticais de ar condicionado. 
O projeto do Ibis Praia de Botafogo selecionou sistemas que priorizassem a rapidez da construção. Dentre eles podemos citar:

$\checkmark \quad$ Sistema de lajes protendidas, eliminando vigas;

$\checkmark \quad$ Sistema otimizado de fôrmas, reduzindo o processo artesanal de carpintaria;

$\checkmark \quad$ Banheiros prontos e vedações em drywall, acompanhando o sistema de divisórias em gesso acartonado usado entre os quartos e com revestimento acústico.

O módulo foi recebido na obra com apenas uma das folhas de drywall, para as instalações elétricas passarem pela parede. No canteiro, a lã de vidro, os reforços para prender elementos de marcenaria, junto com a segunda folha de gesso acartonado foram instalados.

Os banheiros foram montados seguindo os procedimentos de nivelamento, prumo e esquadro mostrados anteriormente.

O modelo do banheiro foi aprovado em junho de $2014 \mathrm{e}$ as primeiras unidades foram recebidas em outubro do mesmo ano. Neste período, cerca de 100 banheiros foram produzidos.

Quando as escoras de um pavimento eram retiradas, este recebia o gesso projetado no teto e estava pronto para a chegada e o posicionamento dos banheiros.

As vantagens do banheiro pronto foram apreciadas durante a construção do Ibis Budget Praia de Botafogo. Não houve problemas com o cronograma, compra de materiais, armazenamento e conferência dos mesmos, mão de obra específica ou retrabalho.

A impermeabilização foi feita com a célula montada, com acabamento arredondado. Posteriormente, a superfície foi limpa para aplicação do primer e da manta asfáltica na espessura de 3 a 4 milímetros, como citado anteriormente. Antes de o revestimento ser colocado foram executados os testes de estanqueidade e caimento. Concluída a impermeabilização, foi feita uma proteção mecânica para nivelamento do piso e proteção da manta asfáltica.

As instalações hidráulicas foram feitas no sistema PEX. Toda a parte hidráulica é direcionada ao shaft, que atende dois banheiros e recebe uma prumada de água fria e água quente.

As prumadas de esgoto também foram projetadas para o shaft atendendo os banheiros que o compartilham, do mesmo modo que as hidráulicas.

Na Figura 5 pode-se observar o Hotel Ibis Budget Praia de Botafogo em construção, sua planta do banheiro-pronto, interligação instalações hidrossanitárias em shafts e a bacia sanitária especificada em projeto. 
Figura 5: A) Ibis Botafogo em construção; B) Planta baixa do banheiro pronto; C) Shaft recebendo as instalações; D) Bacia sanitária utilizada no Ibis Budget.
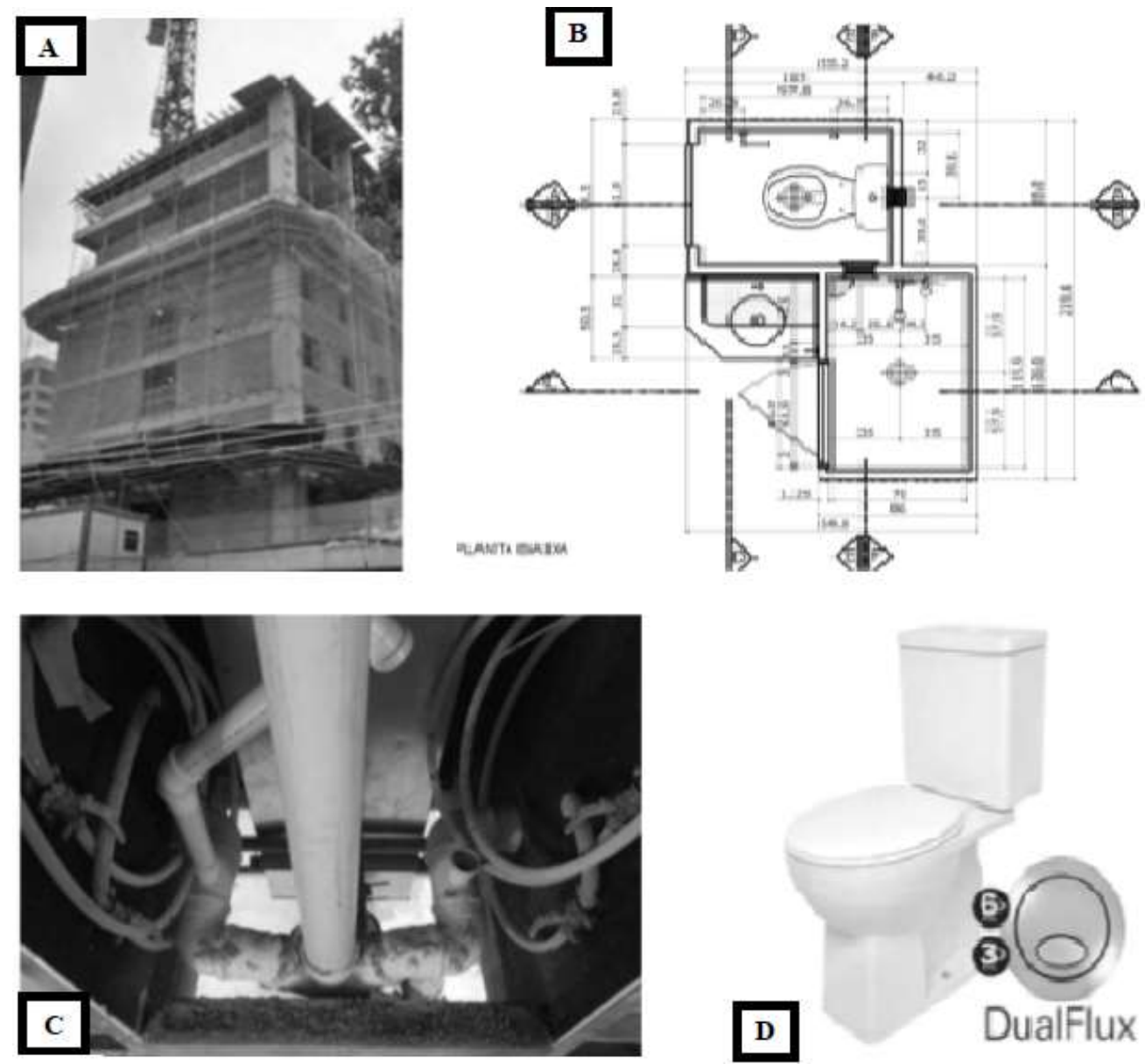

Fontes: 5A e C)Pinheiro, Gabriela; B)Tecnobagno; D)Deca.

O Hotel Ibis Bugdget Praia de Botafogo teve seu processo de construção iniciado em 2014 e finalizado em 2016, Figura 5A.

Analisando a planta do pavimento/banheiro nota-se imprescindível que as medidas do projeto sejam seguidas, caso contrário, a colocação das portas dos quartos ou o espaço do corredor e dos dormitórios seria prejudicado, Figura 5B.

Um aspecto que deve ser analisado na fase inicial é o shaft, pois o projetista deve atentar para as prumadas do banheiro e dutos verticais de ar condicionado e incêndio, que dividirão o referido espaço, Figura 5C.

A bacia sanitária empregada no Ibis Praia de Botafogo possui saída horizontal, com caixa acoplada e descarga do tipo dual flux, Figura 5D. As instalações elétricas seguem os padrões do banheiro convencional.

Os banheiros ganharam revestimentos cerâmicos, segundo padrão da rede Ibis Budget, cinza no piso e branco nas paredes do box e da bacia sanitária. Nas portas foram aplicadas soleiras de granito.

Para evitar transtornos no trânsito os banheiros foram entregues de madrugada. As carretas encarregadas do transporte dos banheiros são de médio porte e carregam 04 banheiros por viagem, o que nos leva a considerar que foram necessárias 06 carretas com 04 banheiros para cada pavimento, totalizando as 24 células consideradas no projeto, divididas em tipos direito e esquerdo.

Na Figura 6, é observado o processo de descarregamento, içamento, posicionamento no andar, o desnível em relação à laje e a visão do corredor. 
Figura 6: A) Banheiros sendo descarregados; B) Banheiro posicionado na plataforma; C) banheiro içado para o pavimento; D) Desnível do banheiro em relação à laje; E) Visão final do corredor.
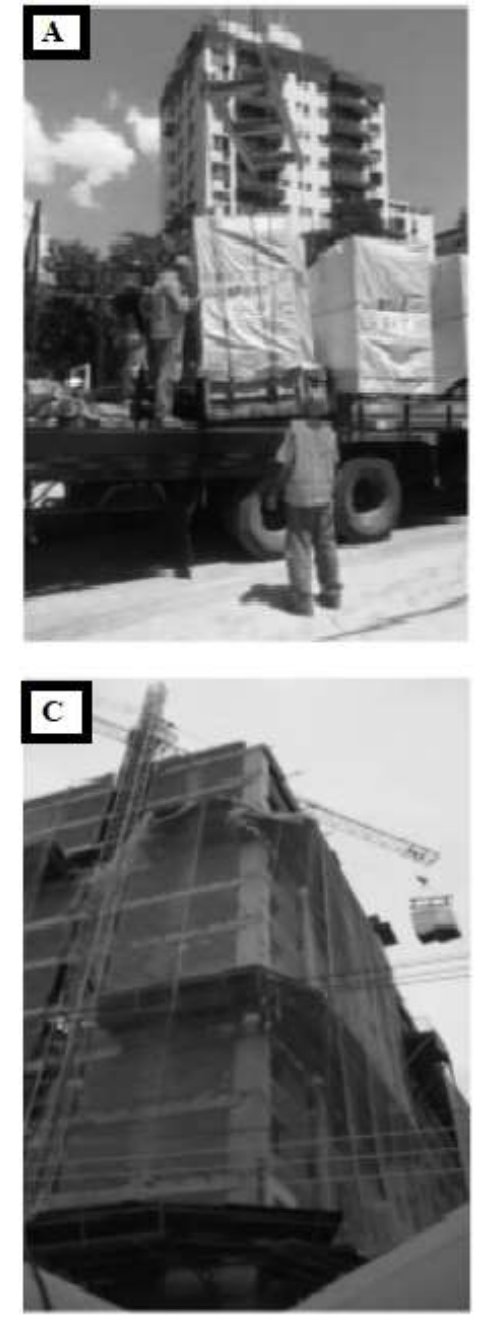
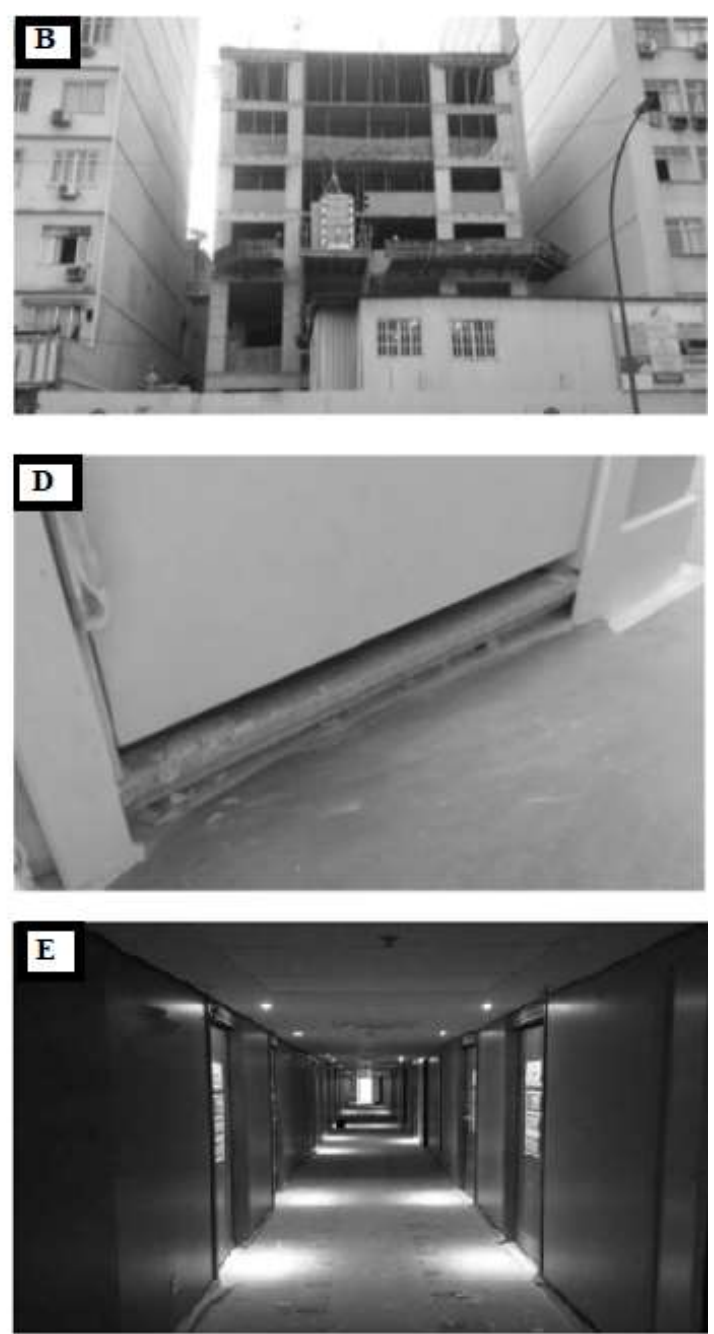

Fonte: Acervo pessoal.

Como mencionado, o transporte é de encargo da construtora, neste caso a Tecnobagno, contudo a escolha e contratação do serviço podem ser feitas também pela obra, Figura 6A.

Quando houve a aprovação do protótipo, em visita anterior feita a fábrica, foi mostrada uma maquete onde foram analisados os meios de transporte vertical dos módulos até os locais definitivos dentro da obra.

No caso do referido hotel, a grua já era necessária para transportar as fôrmas, com componentes metálicos extremamente pesados, por isso preferiu-se utilizar a grua para o transporte vertical dos banheiros, Figura 6B.

A grua é requerida por diversas frentes, como por exemplo, o transporte das fôrmas, para os paletes de blocos cerâmicos e materiais diversos, concreto para os pilares e para o banheiro pronto. Caso essas ações não sejam programadas o trabalho pode sofrer atrasos e prejudicar o cronograma da obra.

Depois de descarregados, os banheiros são içados ao pavimento correspondente com a grua e posicionados na plataforma para daí então, serem dispostos no carrinho e levados ao local de instalação, Figura 6C.

Nesta fase cabe ressaltar a necessidade de precisão na altura do pé direito e o vão da alvenaria de fachada para que não haja problemas no transporte dos banheiros pelo pavimento. Caso a laje seja muito espeça ou o banheiro tenha dimensões erradas, a locomoção do módulo fica comprometida.

Quando a plataforma é utilizada só deve ser movimentada para o próximo pavimento após o posicionamento definitivo 
de todos os banheiros, porque o carrinho que locomove dos módulos precisa subir para receber os próximos banheiros.

O próximo passo é posicionar as células e fazer o nivelamento conforme as determinações do projeto. A construtora é responsável por fornecer o alinhamento da célula no pavimento feito com uma linha de nylon esticada no sentido do corredor e marcações perpendiculares pintadas na laje. Esse procedimento é executado por carpinteiros, com supervisão do mestre e aferido pela equipe técnica da obra.

O nivelamento das células de banheiro foi feito com placas de neoprene, conforme mencionado, sendo responsável pelo acabamento entre o banheiro e o restante do quarto. O lavatório não é compartimentado, fazendo parte do quarto, deste modo, o arremate de piso deve ser preciso, sem degraus entre o dormitório e o banheiro.

Foi adotado no Hotel Ibis Budget Praia de Botafogo como solução arquitetônica uma soleira em granito e foi descido o alizar até o piso ficar paralelo com o rodapé, Figura 6D.

Um dos banheiros que compartilham um shaft é alinhado e nivelado. Para o posicionamento do segundo banheiro é necessário que seja feita a vedação de drywall entre os módulos e entre o banheiro e o shaft. As placas precisam ser cortadas para que as prumadas incidam sem danos e os espaços não afetem o revestimento acústico entre os quartos.

Com os dois banheiros posicionados, o contrapiso autonivelante é instalado e são vedadas todas as frestas entre as portas provisórias e o piso do banheiro para evitar danos ao mesmo.

Os shafts são preparados e pintados. Posteriormente os responsáveis pelo serviço de ligação das prumadas, instalações e vedações entre quartos iniciam seus trabalhos.

Durante a obra verificamos que o trabalho segue um ciclo, pelos pavimentos, do transporte até os acabamentos.

Após o posicionamento dos banheiros e nivelamento é feita a primeira análise, chamada de Inspeção Visual onde a construtora verifica os acabamentos e acessórios usados nos banheiros e se estão de acordo com os especificados no projeto, se falta algo ou se houve algum dano. Todas as unidades são vistoriadas e identificadas nos formulários.

Dois documentos são elaborados por banheiro, um é fornecido pela Tecnobagno, preenchido na obra durante a vistoria e em seguida retorna para fábrica. $\mathrm{O}$ outro faz parte do controle de qualidade da construtora.

Esta primeira vistoria é importante, pois se algo faltar ou estiver em desacordo, os próximos módulos já poderão vir de forma correta.

Pequenas inconveniências são resolvidas diretamente na obra pelos assistentes da Tecnobagno, como algumas falhas nos rejuntes e acessórios mal fixados. Em caso de substituição, são conferidas as quantidades necessárias e em num futuro envio de banheiros, a empresa expede o material.

É testado o caimento dos ralos e se as conexões da pia proporcionam algum vazamento ou obstrução. A aferição é feita jogando água no local e segurando na saída do shaft. Posteriormente é feita uma nova inspeção quando o banheiro estiver em condições para funcionamento; com as redes elétrica e hidráulica ligadas. Neste caso, qualquer manutenção é responsabilidade da fabricante.

Na referida obra foi utilizada uma ficha de checagem por pavimentos, diferente da fornecida pela Tecnobagno. No documento, os banheiros foram dispostos no papel, assim como eram no corredor, facilitando o trabalho do assistente que precisa encontrar o banheiro no pavimento para realizar os reparos.

Após o posicionamento final dos banheiros, interligação e conexões das instalações pertinentes e testes elétricos e de estanqueidade, dá-se a permissão para execução do acabamento dos corredores, Figura 6E.

\subsection{Comparação entre o método pré-fabricado e o método convencional}

O Quadro a seguir determina o tempo que foi gasto na instalação os banheiros prontos no Ibis Budget. 
Quadro 1: Tempo de instalação dos banheiros pré-fabricados

\begin{tabular}{|c|c|c|}
\hline \multirow{3}{*}{ Serviço } & Tempo por & Tempo por \\
\hline & & \\
\hline & banheiro & pavimento \\
\hline Transporte do caminhão ao pavimento tipo & $10 \mathrm{~min} / \mathrm{uni}$ & $4 \mathrm{~h}$ \\
\hline Posicionamento dos banheiros de 1 lado do shaft & $20 \mathrm{~min} / \mathrm{uni}$ & $8 \mathrm{~h}$ \\
\hline Fechamento de drywall entre banheiros & $12,5 \mathrm{~min} / \mathrm{uni}$ & $5 \mathrm{~h}$ \\
\hline Posicionamento do banheiro no outro lado do shaft & $7,5 \mathrm{~min} / \mathrm{uni}$ & $3 h$ \\
\hline
\end{tabular}

Fonte: Pinheiro, Gabriela G.

Verifica-se que para a instalação dos módulos em um pavimento são necessários 02 dias e meio de trabalho. Também foi elaborado um orçamento junto à construtora para saber os valores do banheiro, produzido de forma convencional, e o préfabricado. Deve-se atentar que o hotel tem padronização internacional, usando assim, os mesmos acabamentos, revestimentos e drywall de outros empreendimentos do mesmo hotel.

A Tecnobagno orçou uma unidade do banheiro em $\mathrm{R} \$ 6.007,32$ (seis mil e sete reais e trinta e dois centavos). A mão de obra foi estipulada em $\mathrm{R} \$$ 5.380,00 (cinco mil trezentos e oitenta reais) por unidade referente aos banheiros Ibis Budget Praia de Botafogo, e a carreta que transporta os banheiros custou R \$ 2.200,00 (dois mil e duzentos reais) à construtora. Temos então um total de R\$11.937,32 (onze mil novecentos e trinta e sete reais e trinta e dois centavos)

Caso a construtora fosse responsável pela compra dos materiais, pela execução e instalação dos banheiros, o valor seria de $\mathrm{R} \$ 9.748,42$ (nove mil setecentos e quarenta e oito e quarenta e dois centavos).

Verifica-se de o banheiro pronto nesta obra em comparação ao banheiro convencional ficou $22 \%$ mais caro, mesmo quando consideramos os custos indiretos relacionados ao banheiro convencional como transporte e armazenagem de materiais.

\section{Considerações Finais}

A Segunda Revolução Industrial auxiliou no desenvolvimento não apenas das máquinas, como também das ideias. Neste contexto, o taylorismo determinava que os funcionários deveriam especializar-se em apenas uma função durante todo o processo produtivo. Já o Fordismo, voltou-se para a produção de esteiras para que os funcionários não precisassem se locomover durante o processo aumentando a produção em larga escala.

O desenvolvimento industrial no Brasil começou no fim do século XIX quando as primeiras indústrias instalaram-se nos pais e ganhou força na primeira administração de Getúlio Vargas e depois com Juscelino Kubitschek que abriu a economia para o capital internacional.

Com este avanço industrial, a construção civil também ganhou novos ares, pois precisava produzir grandes construções em pouco tempo e com poucos recursos por conta dos estragos causados pela Segunda Guerra Mundial. Houve o início da substituição dos homens pelas máquinas.

Não se pode afirmar quando teve origem os pré-fabricados, mas no século XX os primeiros painéis foram construídos. Conceituam-se pré-fabricados como elementos pré-moldados, executados industrialmente, mesmo em instalações temporárias no canteiro de obras, sob condições rigorosas de controle de qualidade.

No contexto atual, a construção civil visa melhorar suas técnicas para atender o crescimento populacional. Um instrumento de racionalização que visa melhorar os processos tradicionais de construção é o banheiro pronto ou pré-fabricado.

Os banheiros são construídos em linha de produção industrial, podendo ser executados com concreto armado ou 
drywall. Todas as etapas de controle de materiais, instalações, acabamento, passam pelo controle de qualidade na própria fábrica, bastando apenas realizar as prumadas de água, esgoto e instalações elétricas no local de instalação definitivo.

Este sistema, geralmente, é usado em grandes empreendimentos que precisam de retorno rápido como hotéis e prédios comerciais. No entanto, já é utilizado em prédios residenciais e hospitais.

É necessária a análise prévia para aplicação dos banheiros prontos, pois precisam de transporte em carretas e a instalação deve ser feita com cremalheiras ou plataforma fixa. Além disso, alguns requisitos são necessários para a sua aplicação como: complemento do pé direito, desnível do banheiro em relação à laje, utilização de neoprene para apoio do banheiro sobre a laje e o vão da fachada que permita sua entrada no pavimento.

Observa-se que o banheiro pronto possui mais vantagens do que desvantagens na sua aplicação, e através de um caso concreto, verificamos sua instalação no Ibis Budget Praia de Botafogo.

Enfim, após estudo minucioso do contexto histórico, sua concepção e aplicação, concluímos que há vantagens no cronograma físico financeiro da obra com a aplicação deste elemento pré-fabricado. Contudo, faz-se imperioso que o referido sistema seja aplicado em grandes empreendimentos que tenham um cronograma curto e com possibilidade de multa em caso de atraso, pois são mais onerosos que os banheiros convencionais.

Tanto clientes quanto a construtora são beneficiados. Aquele ganhou em qualidade, sem atrasos na obra e padronização aliada ao controle rigoroso de qualidade. A construtora foi liberada da compra de vários materiais referentes ao banheiro e, com isso, obteve menos retrabalho, resíduos e estocagem de materiais, o que torna o canteiro de obras mais limpo e o trabalho mais rápido. A aplicação do banheiro pronto diminui em, aproximadamente, 04 meses o cronograma da obra.

Obras de pequeno porte e sem necessidade de prazo o método torna-se oneroso, pois o banheiro "in loco", neste tipo de empreendimento é mais econômico.

O banheiro pronto ainda é pouco utilizado nos dias atuais, entretanto a ampla divulgação desta tecnologia deve estimular novos produtores a desenvolver tecnologias mais baratas e mais construtoras a conhecerem o método, fomentando com isso, a possibilidade de ampliação do seu uso em todos os tipos de construções.

A aplicação do planejamento na aplicação do cronograma físico-financeiro na construção civil visa a viabilidade da realização do empreendimento de acordo com o objetivo esperado com cumprimento da previsão de tempo e custo, porém este custo de planejamento deve constar como item principal na realização de uma construção civil. Pode ser feito, também, uma integração entre outros formatos como cozinhas prontas e não somente em hotéis, mas também em residenciais multifamiliares.

\section{Referências}

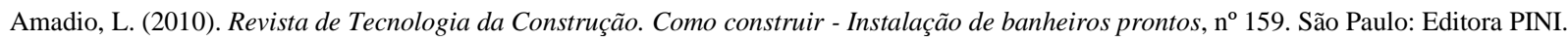

Amadio, L. (2014). Revista de Tecnologia da Construção. Como construir-Conheça os cuidados no projeto e na execução de banheiros prontos, $\mathrm{n}^{\circ} 210$. São Paulo: Editora PINI.

Barbosa, N. (2015). Construção e Mercado. Banheiros Prontos. nº 173. São Paulo: Editora PINI.

Barth, F., Vasconcelos, A. C., Bunn, J., \& Becsi, P. (2009). Desenvolvimento de banheiro pré-fabricado voltado para construções emergenciais. In: $2^{\circ}$ Encontro Nacional de Pesquisa-Projeto-Produção em Concreto Pré-moldado, São Carlos, SP.

Blachére, G. (1977). Tecnologias da Construção Industrializada. Coleção Tecnologia y Arquitetura - Espanha: Editora Gustavo Gilli.

Brumatti, D. O. (2008) Uso de pré-moldado - estudo e viabilidade: TCC Engenharia civil, Universidade Federal de Minas Gerais, Vitória.

Bruna, P. J. V. (1976). Arquitetura, Industrialização e Desenvolvimento - São Paulo: Editora Perspectiva,.

Buckminster, F. R. (1940). Inventor: Phelps Dodge Corp, assignee. Prefabricated Bathroom. United States patent US 2220482 A.

Camargo, A. R. (1975). Industrialização da construção no Brasil. Dissertação (mestrado em arquitetura) Escola de Engenharia de São Carlos. Universidade de São Paulo. 
Research, Society and Development, v. 11, n. 1, e27811124650, 2022

(CC BY 4.0) | ISSN 2525-3409 | DOI: http://dx.doi.org/10.33448/rsd-v11i1.24650

Cichinelli, G. (2015). Revista de tecnologia da construção. Construtora aposta em soluções industrializadas na construção dos edifícios do empreendimento Parque da Cidade. São Paulo. No 225. São Paulo: Ed. PINI.

Elliot, R. S. (2002). Precast Frame concepts, economics and Architetural Requirements. In Workshop on Design \& Constrution precast Croncrete Structures. Construction Industry Trading Institute. Singapore.

Estrela, C. (2018). Metodologia Científica: Ciência, Ensino, Pesquisa. Editora Artes Médicas.

Ferreira, F. do E. S. R. ., \& Magalhães, E. M. . (2021). Utilização do ciclo PDCA para melhoria de qualidade e aumento de produtividade em uma multinacional do polo industrial de Manaus. Research, Society and Development, 10(13), e524101321609. https://doi.org/10.33448/rsd-v10i13.21609

Franco, L. S. (1992). Aplicação de diretrizes de racionalização construtiva para a evolução tecnológica dos processos construtivos em alvenaria estrutural não armada. (Doutorado em Engenharia Civil) - Escola Politécnica da Universidade de São Paulo. São Paulo.

Garcia, C. (2010). Revista Tapume. Banheiros Prontos. nº 98, Jornal dos colaboradores da HOCHTIEF do Brasil

Kume, C. M. (2001). Industrialização da produção de banheiros, tese de MBA, São Paulo: Politécnica USP.

Martins, M. G., \& Barros, M. S. B. (2003). A formação de parcerias como alternativa para impulsionar a inovação na produção de edifícios. III Simpósio Brasileiro de Gestão e Economia da Construção. São Carlos.

Lopes, R.D. (2005). Banheiro Pronto. TCC Engenharia Civil, Universidade Anhembi Morumbi. São Paulo.

Loturco, B. (2005). Revista de Tecnologia da Construção. Pré-fabricados. № 99. São Paulo: Ed. PINI.

Ludke, M. \& Andre, M. E . D. A. (2013). Pesquisas em educação: uma abordagem qualitativa. São Paulo: E.P.U.

Oliveira, L.A. (2002). Tecnologia de painéis pré-fabricados arquitetônicos de concreto para emprego em fachadas de edifícios. Dissertação de Mestrado Escola Politécnica, Universidade de São Paulo, São Paulo.

Oliveira, P. V. H. (1999). Análise da aplicação de check-list sobre inovações tecnológicas em canteiros de obra. Universidade Federal de Santa Catarina.

Ordonéz, J. A. F. (1974) Pre-fabricacion: teoría y prática. v.1. Barcelona: Editores Técnicos Associados.

Pereira, A. S., Shitsuka, D. M., Parreira, F. J. \& Shitsuka, R. (2018). Metodologia da pesquisa científica. [free e-book]. Santa Maria/RS. Ed. UAB/NTE/UFSM.

Pinheiro, G. G. (2015). Banheiro Pronto Viabilidade técnica e econômica. TCC. Engenharia Civil, Universidade Federal do Rio de Janeiro. Rio de Janeiro, 2015 .

Salas, S. J. (1988). Construção industrializada: pré-fabricados. Instituto de pequenas tecnologias São Paulo.

Santos, O. S. dos, Correia, L. A., Conceição, M. M., \& Morais, M. de O. (2020). Processo de melhoria contínua: estudo de caso aplicado em uma empresa gráfica. Research, Society and Development, 9(9), e101997204. https://doi.org/10.33448/rsd-v9i9.7204

Serra, S.M.B., \& Ferreira, M.de A., \& Pigozza, B.N. (2005). A evolução da indústria da construção civil em função do uso de pré-fabricados de concreto. $1^{\circ}$ encontro de pesquisa, projeto, produção em concreto pré-moldado, São Paulo.

Vasconcelos, A. C. (2002). O Concreto no Brasil: pré-fabricação, monumentos, fundações. Volume III. Ed. Studio Nobel.

Yin, R.K. (2015). O estudo de caso. Porto Alegre: Bookman.

Associação Brasileira de Normas Técnicas (1998). NBR 14037: Manual de operação, uso e manutenção das edificações - Conteúdo e recomendações para elaboração e apresentação.

Associação Brasileira de Normas Técnicas. (1985). NBR 9062: Projeto e execução em estruturas de concreto pré-moldado.

Associação Brasileira da Construção Industrializada. (1980). A História dos pré-fabricados e sua evolução no Brasil.

Arroba Casa (2021). Jardins De France - Jardins De Villandry Condomínio Edifício. http://www.arrobacasa.com.br/jardins-de-france-jardins-de-villandrybrooklin.

AECweb (2021). Banheiros prontos: logística é crucial. http://www.aecweb.com.br/cont/m/rev/banheiros-prontos-logistica-e-crucial_.

Terra Magazine (2021). Tecnologia Construtiva em obra na reserva do Paiva. http://www.terramagazine.com.br/tecnologia-construtiva-em-obra-na-reservado-paiva/

Construnormas (2021). Mantas asfálticas.. http://construnormas.pini.com.br/engenharia-instalacoes/impermeabilizacao/mantas-asfalticas-342437-1.aspx

Tecnobagno (2021). Banheiro pronto. www.banheiropronto.com.br

Deca (2021). Banheiros. www.deca.com.br 